\title{
Prey preference and biomass consumption of Macrolophus pygmaeus (Hemiptera: Miridae) fed Myzus persicae and Macrosiphum euphorbiae (Hemiptera: Aphididae)
}

\author{
DionysSios P. LYKOURESSIS, DionYsSIOS CH. PERDIKIS and MARIA D. GASPARI
}

Agricultural University of Athens, Laboratory of Agricultural Zoology and Entomology, Iera Odos 75, 11855 Athens, Greece; e-mail: lykouressis@aua.gr

Key words. Miridae, Aphididae, aphid, Macrosiphum euphorbiae, Myzus persicae, biological control, predation, prey preference, biomass consumption, mirid bug, Macrolophus pygmaeus

\begin{abstract}
The predation rate of the polyphagous predator Macrolophus pygmaeus (Rambur) when offered two aphid species, Myzus persicae (Sulzer) and Macrosiphum euphorbiae (Thomas), was investigated. Equal or unequal numbers of nymphs of each instar of the aphids were offered to the predator alone or together. Aphids were placed on an eggplant leaf, together with a fifth instar nymph of the predator in a plastic Petri dish and kept in growth cabinets at $25^{\circ} \mathrm{C}, 65 \pm 5 \%$ r.h., and a $16 \mathrm{~L}: 8 \mathrm{D}$ photoperiod. The predation rate of M. pygmaeus was always higher on M. persicae than on M. euphorbiae. However, biomass consumption was highest when instars of M. euphorbiae were offered in unequal numbers. The predator showed a strong preference and higher biomass consumption of first and second instar M. persicae. In tests where M. euphorbiae was the prey, preference and biomass consumption were almost always higher for the first instar. Therefore, first and second instar M. persicae and first instar M. euphorbiae provide optimal prey for M. pygmaeus. The implication of the prey preference shown by M. pygmaeus for the biological control of these two aphid species is discussed.
\end{abstract}

\section{INTRODUCTION}

Polyphagous predators of the genus Macrolophus (Hemiptera: Miridae) are effective biological control agents of several key pests of vegetable crops (Albajes \& Alomar, 1999). Macrolophus pygmaeus (Rambur) develops successfully on Myzus persicae (Sulzer) and Macrosiphum euphorbiae (Thomas) (Hemiptera: Aphididae), which are important pests of eggplant and tomato (Perdikis \& Lykouressis, 2000). In the absence of arthropod prey this predator can develop successfully as a herbivore feeding on leaves of eggplant and other vegetables (Perdikis \& Lykouressis, 2000; Lykouressis et al., 2001). M. pygmaeus is the most important natural enemy of aphids on tomato crops in central Greece (Lykouressis et al., 2000a) and commonly recorded on vegetable crops, including eggplant (Lykouressis et al., 2000b).

In biological control programmes, the predation rate of a predator is an important indicator of its possible effectiveness in suppressing pest populations. The predation rate of $M$. pygmaeus fed various instars of $M$. persicae is highest at $30^{\circ} \mathrm{C}$, and females and fifth instar nymphs are the most voracious (Perdikis et al., 1999). However, these results are for $M$. pygmaeus offered a single prey species, while under natural conditions, predators normally encounter a range of prey species. Therefore, studies of predation in which different prey types are simultaneously offered might more accurately represent a predator's performance in the field. The feeding preference of a predator offered different types of prey is largely governed by the ratio of energy obtained relative to the costs of searching and consuming the prey (Krebs \& McCleery,
1984). All of these constraints are closely related to prey size but also prey behaviour.

The aim of this study was to determine the influence of prey species and prey size on the predation and consumption rate of $M$. pygmaeus when two species of prey were offered either alone or together. This was investigated by using all four instars of M. persicae and M. euphorbiae, offered in equal or unequal numbers (i.e. proportions). Three questions were addressed: (1) Does M. pygmaeus choose between the two aphid species; (2) Is the preference of $M$. pygmaeus affected by the proportions of instars available (equal or unequal numbers) and (3) Is the prey-choice behaviour of $M$. pygmaeus affected by the biomass of each prey instar available?

\section{MATERIAL AND METHODS}

Macrolophus pygmaeus adults and nymphs were collected from a tomato field in Co. Boeotia, central Greece, and reared on potted eggplants cv. Bonica, infested with M. persicae. Cultures of both prey species, M. persicae and M. euphorbiae, were established on eggplants cv. Bonica. Stock colonies were kept in woodframed cages (length $80 \mathrm{~cm} \times$ width $80 \mathrm{~cm} \times$ height 70 $\mathrm{cm}$ ), in a glasshouse maintained at $22.5 \pm 2.5^{\circ} \mathrm{C}$ (mean \pm S.D.) under natural lighting.

Prey choice was tested by offering equal or unequal numbers of nymphs of each instar of one or both aphid species, to a fifth instar nymph of M. pygmaeus. In one test series, ten nymphs of each of the four instars of $M$. persicae or M. euphorbiae were used, either each species separately (40 nymphs in total) or both species together (40 nymphs of each species, i.e. 80 nymphs in total). In the latter case, for comparability, the total number of nymphs of a particular aphid species was the same as that when 
each species of prey was offered alone (40 nymphs of each species).

In the experiments, the number of aphids available to the fifth instar nymphs of the predator was much higher than its recorded predation rate (Perdikis et al., 1999).

In the remaining series of experiments, unequal numbers of nymphs of each aphid instar were used to simulate increasing aphid populations. For this reason, the number of nymphs of each instar was adjusted so that the percentage of the total biomass made up of each aphid instar remained constant between the two aphid species. The average weight of each instar was estimated by weighing groups of 40 live nymphs of each instar of $M$. persicae and 20 nymphs of each instar of $M$. euphorbiae, previously anaesthetized with carbon dioxide. This was replicated three times for each instar using a Mettler Toledo AB204-S with a precision of $0.1 \mathrm{mg}$. The weight of the aphid remains was ignored in estimating consumption. The mean group weight $( \pm \mathrm{SE})$ of each instar was: $0.9 \pm 0.01,2.0 \pm 0.21$, $3.17 \pm 0.08$ and $5.17 \pm 0.23 \mathrm{mg}$ for M. persicae and $1.03 \pm 0.09$, $2.30 \pm 0.06,3.93 \pm 0.32$ and $6.43 \pm 0.52 \mathrm{mg}$ for M. euphorbiae. The average weight of first, second, third and fourth instar $M$. persicae was estimated as $0.0225,0.0505,0.0793$ and 0.1293 $\mathrm{mg}$ and $0.0515,0.1150,0.1965$ and $0.3215 \mathrm{mg}$ for $M$. euphorbiae. The following number of prey were used: (a) 18 first, 11 second, 8 third and 3 fourth instar of $M$. persicae, giving a total of 40 nymphs; (b) 19 first, 11 second, 7 third and 3 fourth instar $M$. euphorbiae, i.e. also 40 nymphs in total; and (c) 18 first, 11 second, 8 third and 3 fourth instar M. persicae together with 19, 11, 7 and 3 equivalent instars M. euphorbiae (80 nymphs in total, and 40 nymphs of each aphid species).

Experiments were conducted in plastic Petri dishes $(9 \mathrm{~cm}$ diameter, $1.5 \mathrm{~cm}$ height). A round ( $3 \mathrm{~cm}$ diameter) hole was cut in the top cover and covered with fine muslin. A leaf of eggplant was placed, abaxial surface uppermost, on a layer of moistened cotton wool in the bottom of each Petri dish. The aphids were then placed gently on the leaf and left for $1 \mathrm{~h}$ to settle, before the introduction of a predator.

Fifth instar nymphs of the predator were used in all experiments. In order to obtain these, first or second instar nymphs of $M$. pygmaeus were reared on eggplants infested with an excess of $M$. persicae, kept at $25^{\circ} \mathrm{C}, 65 \pm 5 \%$ r.h. and a $16 \mathrm{~L}$ : 8D photoperiod. In the experiments, fifth instar nymphs of $M$. pygmaeus greater than one day old were used. Data for any nymph that moulted during the experiments was discarded, as moulting clearly affected the feeding rate.

After the introduction of a single nymph of M. pygmaeus into each dish, the dishes were placed in a growth cabinet at the same conditions as above. In each experiment 25 nymphs (replicates) of the predator were used. The number of aphids con- sumed was counted $24 \mathrm{~h}$ later. The foraging behaviour of the predator was not recorded during the experiment. This predator sucks out the contents of an aphid leaving only their skin. In a small number of cases partially consumed aphids were recorded, which were allocated a score of 0.5 . Preliminary experiments showed that there was negligible aphid mortality in the absence of the predator.

The use of predation rate (the number of aphids consumed / $24 \mathrm{~h}$ ) to evaluate a predator's preference for different prey was based on Manly's preference index (Manly et al., 1972), which takes into account the depletion of prey due to predation (Chesson, 1983). Manly's preference index is given by:

$$
\beta \mathrm{j}=\frac{\ln (r j / A j)}{\sum_{j=1}^{4} \ln (r j / A j)}, \mathrm{j}=1,2,3,4
$$

where $\beta \mathbf{j}=$ Manly's Beta for aphid instar $\mathbf{j}, r j=$ the number of individuals in aphid instar $\mathrm{j}$ not selected by the predator and $A j$ the number of individuals in aphid instar $\mathrm{j}$ available to the predator. The Manly's index values for each aphid instar were examined for significant departure from expectation (i.e. the ratio of the number of individuals of the respective instar to the total number of aphid individuals available to the predator in each test i.e. 0.25 ) by using a t-test. This index was also used to evaluate the preference of the predator for the different prey items by considering the biomass consumed vs. the biomass available in each case.

The data on predation rate and consumption (measured as biomass consumed), were analyzed using either 1 or 2-way ANOVA with factors the equal vs. unequal numbers, the aphid instar or the aphid species. Means were separated using the Tukey-Kramer (HSD) test $(\mathrm{P}=0.05)$. The data on predation rate were square-root transformed before analysis. The relationship between the biomass of each instar consumed and the mean weight of a single individual of a given instar was calculated in each experiment. Statistical analyses were conducted using the statistical package JMP IN (SAS Institute, 2001).

\section{RESULTS}

The predation rate of $M$. pygmaeus on $M$. persicae was consistently higher than on $M$. euphorbiae when these species were offered separately or together in equal or unequal numbers (Table 1).

When unequal numbers of each aphid instar of a species were offered, the predator ate a significantly greater biomass of $M$. euphorbiae than of $M$. persicae (Table 1). However, when both species were offered together, a

TABLE 1. Predation rate and biomass (mean $\pm \mathrm{SE}$ ) consumed by fifth instar nymphs of Macrolophus pygmaeus when offered nymphs of each instar of Myzus persicae and Macrosiphum euphorbiae either alone or together in equal or unequal numbers.

\begin{tabular}{|c|c|c|c|c|}
\hline & \multicolumn{2}{|c|}{ One species alone } & \multicolumn{2}{|c|}{ Two species together } \\
\hline & M. persicae & M. euphorbiae & M. persicae & M. euphorbiae \\
\hline & & Pre & & \\
\hline \multirow{3}{*}{$\begin{array}{l}\text { Equal number } \\
\text { Unequal number }\end{array}$} & $9.22 \pm 0.64 \mathrm{Aa}$ & $5.28 \pm 0.38 \mathrm{Ba}$ & $7.80 \pm 0.54 \mathrm{Aa}$ & $3.26 \pm 0.25 \mathrm{Ba}$ \\
\hline & $10.66 \pm 0.85 \mathrm{Aa}$ & $7.48 \pm 0.38 \mathrm{Bb}$ & $8.23 \pm 0.71 \mathrm{Aa}$ & $3.16 \pm 0.32 \mathrm{Ba}$ \\
\hline & \multicolumn{4}{|c|}{ Biomass } \\
\hline Equal number & $0.47 \pm 0.04 \mathrm{Aa}$ & $0.51 \pm 0.04 \mathrm{Aa}$ & $0.43 \pm 0.04 \mathrm{Aa}$ & $0.25 \pm 0.03 \mathrm{Ba}$ \\
\hline Unequal number & $0.43 \pm 0.04 \mathrm{Aa}$ & $0.57 \pm 0.04 \mathrm{Ba}$ & $0.33 \pm 0.03 \mathrm{Ab}$ & $0.22 \pm 0.02 \mathrm{Ba}$ \\
\hline
\end{tabular}

Values with the same upper case letters were not significantly different for the two aphid species in each treatment. Values with the same lower case letters were not significantly different when nymphs of a given species were offered in equal or unequal numbers in each treatment. 
TABLE 2a. Predation rate (mean \pm SE) of fifth instar nymphs of Macrolophus pygmaeus when offered 10 nymphs of each instar of Myzus persicae and Macrosiphum euphorbiae alone or together.

\begin{tabular}{lccccc}
\hline & \multicolumn{2}{c}{ One species alone } & & \multicolumn{2}{c}{ Two species together } \\
\cline { 2 - 3 } \cline { 5 - 6 } Instar & M. persicae & M. euphorbiae & & M. persicae & M. euphorbiae \\
\hline First & $3.54 \pm 0.34 \mathrm{a}$ & $3.24 \pm 0.28 \mathrm{a}$ & & $2.80 \pm 0.24 \mathrm{Aa}$ & $2.22 \pm 0.21 \mathrm{Aa}$ \\
Second & $3.00 \pm 0.37 \mathrm{ab}$ & $1.24 \pm 0.20 \mathrm{~b}$ & & $2.48 \pm 0.23 \mathrm{Aa}$ & $0.80 \pm 0.19 \mathrm{Bb}$ \\
Third & $1.96 \pm 0.18 \mathrm{~b}$ & $0.64 \pm 0.14 \mathrm{bc}$ & & $1.72 \pm 0.22 \mathrm{Ab}$ & $0.24 \pm 0.13 \mathrm{Bc}$ \\
Fourth & $0.68 \pm 0.18 \mathrm{c}$ & $0.24 \pm 0.09 \mathrm{c}$ & & $0.80 \pm 0.18 \mathrm{c}$ & 0.00 \\
\hline
\end{tabular}

Values with the same lower case letters were not significantly different among instars (within each column). Values with the same upper case letters were not significantly different between species for a given instar when both species were offered together.

greater biomass of M. persicae was consumed than of $M$. euphorbiae.

In the experiments where equal numbers of each instar of a species were offered the predation rate was higher on first and second instar $M$. persicae and first instar $M$. euphorbiae $\left(F_{3,96}=26.16, p<0.01\right.$ and $F_{3,96}=47.70, p<$ 0.01 , for each aphid species, respectively) (Table 2a).

The values of Manly's preference index were significantly higher than those expected for first and second instar M. persicae and first instar M. euphorbiae (Table 2b).

When equal numbers of each instar of both prey species were offered together, there was a significant interaction between "species" and "instar" $\left(F_{3,192}=5.25, p<0.01\right)$ indicating that the predation rate on the instars of the two prey species differed. Significantly more second, third and fourth instar nymphs of M. persicae were consumed than those of M. euphorbiae (Table 2a).

When both species were present, Manly's preference index for first and second instar M. persicae and first instar M. euphorbiae were higher than expected indicating the predator's preference for early instars. First instar nymphs of $M$. euphorbiae were preferred to those of M. persicae (Table 2b).

In the experiments using unequal numbers of each instar, when each species was offered alone, the predator preyed on a significantly higher number of first instar nymphs of both aphid species $\left(F_{3,96}=65.26, p<0.01\right.$ and $F_{3,96}=139.6, p<0.01$, in M. persicae and M. euphorbiae, respectively) (Table 3a). Preference was higher than that expected for second instar M. persicae and first instar $M$. euphorbiae (Table 3b).
When both aphid species were offered in unequal numbers, there was a significant interaction between "species" and "instar" $\left(F_{3,192}=8.06, p<0.01\right)$. The total numbers of first, second and third instar $M$. persicae consumed were significantly greater than those of $M$. euphorbiae (Table 3a). M. pygmaeus showed a preference for second instar M. persicae and first instar M. euphorbiae (Table 3b).

The biomass consumed by the predator when each aphid species was offered alone in equal numbers was higher for second and third instar M. persicae but similar for first, second and third instar M. euphorbiae $\left(F_{3,96}=\right.$ $5.72, p<0.01, F_{3,96}=2.50, p=0.06$, respectively) (Table $4)$. The values of Manly's index were significantly higher than expected for first and second instar M. persicae and for the first instar M. euphorbiae (Table 2b).

When both species were offered to the predator in equal numbers, biomass consumption was affected significantly by "species" and "instar" $\left(F_{3,192}=8.36, p<0.01\right)$. A greater biomass of second and third instar $M$. persicae and first and second instar M. euphorbiae was consumed (Table 4). The values of Manly's preference index were significantly higher than those expected for first and second instar M. persicae and first instar M. euphorbiae (Table 2b).

When unequal numbers of nymphs of each instar of one species were present, the biomass consumption was highest for second instar $M$. persicae and first instar $M$. euphorbiae $\left(F_{3,96}=17.6, p<0.01\right.$ and $F_{3,96}=25.1, p<$ 0.01 , respectively) (Table 5). The values of Manly's preference index were significantly higher than those expected for first and second instar M. persicae and for first instar M. euphorbiae (Table 3b).

TABLE 2b. Manly's index (mean $\pm \mathrm{SE}$ ) when 10 nymphs of each instar of Myzus persicae and Macrosiphum euphorbiae were offered, alone or together, to fifth instar Macrolophus pygmaeus.

\begin{tabular}{|c|c|c|c|c|}
\hline \multirow[b]{2}{*}{ Instar } & \multicolumn{2}{|c|}{ One species alone } & \multicolumn{2}{|c|}{ Two species together } \\
\hline & M. persicae & M. euphorbiae & M. persicae & M. euphorbiae \\
\hline First & $0.40 \pm 0.03 * * * / \mathrm{xxx}$ & $0.65 \pm 0.04 * * * / \mathrm{xxx}$ & $0.37 \pm 0.02 * * * / \mathrm{xxx}$ & $0.71 \pm 0.06^{* * *} / \mathrm{xxx}$ \\
\hline Second & $0.33 \pm 0.03 * / \mathrm{xxx}$ & $0.20 \pm 0.03$ & $0.32 \pm 0.02 * * / \mathrm{xxx}$ & $0.23 \pm 0.06$ \\
\hline Third & $0.21 \pm 0.02 / \mathrm{xxx}$ & $0.09 \pm 0.03 * * * / \mathrm{xxx}$ & $0.22 \pm 0.03 / x$ & $0.05 \pm 0.03 * * * / \mathrm{xxx}$ \\
\hline Fourth & $0.05 \pm 0.01 * * * / \mathrm{xxx}$ & $0.05 \pm 0.02 * * * / \mathrm{xxx}$ & $0.08 \pm 0.00^{* * *} / \mathrm{xxx}$ & 0.00 \\
\hline
\end{tabular}

Significant differences between the estimated and expected values of Manly's index; in terms of numbers expected values are always 0.25 , significant differences are indicated by asterisks, $*: P<0.05, * *: P<0.01$, ***: $P<0.001$.; in terms of biomass consumed the expected values are: $0.08,0.18,0.28,0.46$ for each instar independent of species, respectively; significant differences are indicated by x: $P<0.05$, xx: $P<0.01$, xxx: $P<0.001$. 
TABLE 3a. Predation rate (mean $\pm \mathrm{SE}$ ) of fifth instar nymphs of Macrolophus pygmaeus when offered 18, 11, 8 and 3 nymphs of each instar of Myzus persicae and 19, 11, 7 and 3 nymphs of each instar of Macrosiphum euphorbiae alone or together.

\begin{tabular}{llcccc}
\hline & \multicolumn{2}{c}{ One species alone } & & \multicolumn{2}{c}{ Two species together } \\
\cline { 2 - 3 } \cline { 5 - 6 } Instar & M. persicae & M. euphorbiae & & M. persicae & M. euphorbiae \\
\hline First & $5.60 \pm 0.49 \mathrm{a}$ & $5.50 \pm 0.36 \mathrm{a}$ & & $4.46 \pm 0.42 \mathrm{Aa}$ & $2.42 \pm 0.28 \mathrm{Ba}$ \\
Second & $3.54 \pm 0.41 \mathrm{~b}$ & $1.46 \pm 0.23 \mathrm{~b}$ & & $2.76 \pm 0.36 \mathrm{Ab}$ & $0.62 \pm 0.16 \mathrm{Bb}$ \\
Third & $1.40 \pm 0.27 \mathrm{c}$ & $0.40 \pm 0.12 \mathrm{c}$ & & $1.00 \pm 0.24 \mathrm{Ac}$ & $0.12 \pm 0.06 \mathrm{Bc}$ \\
Fourth & $0.12 \pm 0.09 \mathrm{~d}$ & $0.12 \pm 0.07 \mathrm{c}$ & & $0.10 \pm 0.06 \mathrm{Ad}$ & 0.00 \\
\hline
\end{tabular}

Values with the same lower case letters were not significantly different among instars (within each column). Values with the same upper case letters were not significantly different between species for a given instar when both species were offered together.

When both aphids were offered together in unequal numbers, $M$. pygmaeus consumed a significantly greater biomass of second instar $M$. persicae and first instar $M$. euphorbiae than other instars $\left(F_{3,96}=13.87, p<0.01\right.$ and $F_{3,96}=19.20, p<0.01$, respectively) (Table 5), whereas a greater biomass of $M$. persicae second and third instars was consumed than of $M$. euphorbiae. The values of Manly's preference index were significantly higher than expected for first and second instar M. persicae and first instar M. euphorbiae (Table 3b).

\section{DISCUSSION}

The predation rate of M. pygmaeus, when M. persicae and $M$. euphorbiae were offered alone, was consistently significantly higher for $M$. persicae than M. euphorbiae (Table 1). Therefore, it seems likely that M. pygmaeus would reduce $M$. persicae numbers more effectively than those of M. euphorbiae. However, when a high percentage of young nymphs of $M$. euphorbiae were offered, as it exists in rapidly increasing populations, the rate of predation by $M$. pygmaeus was significantly higher than when the same numbers of each instar of this prey species was offered, whereas for M. persicae, predation rates did not change (Table 1). However, M. euphorbiae is a much larger aphid than $M$. persicae. Thus, if the predation rate is expressed in terms of biomass consumed, then biomass gain was significantly higher when feeding on $M$. euphorbiae than on M. persicae (Table 1). Thus, the potential of $M$. pygmaeus to suppress $M$. euphorbiae numbers is largely dependent on the structure of M. euphorbiae population. Changes in the ratio of prey types available [eggs of Trialeurodes vaporariorum Westwood (Hemiptera: Aleyrodidae) and eggs of Tetranychus urticae
Koch (Acarina: Tetranychidae)] are also reported to affect the predation rate of the predator Macrolophus caliginosus Wagner (Enkegaard et al., 2001).

When both aphid species were offered simultaneously to M. pygmaeus, the predation rate on M. persicae was more than twice that on M. euphorbiae (Table 1). Therefore, M. pygmaeus can choose between M. persicae and M. euphorbiae. Thus, on eggplant and tomato crops infested with both aphids M. pygmaeus should suppress $M$. persicae numbers more effectively than those of $M$. euphorbiae.

In the present investigation, M. pygmaeus was reared on M. persicae prior to the experiments and this may have resulted in the preference for $M$. persicae compared to $M$. euphorbiae. However, feeding on different prey prior to the experiments did not alter the prey preference of the predator Coccinella septempunctata L. (Coleoptera: Coccinellidae) (Evans et al., 2004). Similarly, rearing of Geocoris punctipes (Say) (Hemiptera: Lygaeidae) on an artificial diet for a long period, did not change its prey preferences compared to that of field-collected predators (Hagler \& Cohen, 1991). In our case, the significance of this effect is probably marginal since $M$. euphorbiae strongly outnumbered $M$. persicae on tomato crops in the area from which the stocks of the predator were collected originally (Lykouressis et al., 2000a; unpubl. data). Based on the present results, this could be related to the preference of M. pygmaeus for M. persicae, since this predator is the main biological control agent of aphids on tomato in this region.

When equal numbers of nymphs of each instar of $M$. persicae were offered, the preference of M. pygmaeus was highest for first followed by second instar individuals

TABLE 3b. Manly's index (mean \pm SE) when 18, 11, 8 and 3 nymphs of each instar of Myzus persicae and 19, 11, 7 and 3 nymphs of each instar of Macrosiphum euphorbiae were offered, alone or together, to fifth instar nymphs of Macrolophus pygmaeus.

\begin{tabular}{|c|c|c|c|c|}
\hline \multirow[b]{2}{*}{ Instar } & \multicolumn{2}{|c|}{ One species alone } & \multicolumn{2}{|c|}{ Two species together } \\
\hline & M. persicae & M. euphorbiae & M. persicae & M. euphorbiae \\
\hline First & $0.39 \pm 0.03 / \mathrm{xxx}$ & $0.60 \pm 0.04^{* *} / \mathrm{xxx}$ & $0.40 \pm 0.04 / \mathrm{xxx}$ & $0.69 \pm 0.06^{* * *} / \mathrm{xxx}$ \\
\hline Second & $0.39 \pm 0.03 * * / \mathrm{xxx}$ & $0.24 \pm 0.03$ & $0.40 \pm 0.04^{* *} / \mathrm{xxx}$ & $0.22 \pm 0.05$ \\
\hline Third & $0.19 \pm 0.04 / \mathrm{xxx}$ & $0.11 \pm 0.03 * / \mathrm{xxx}$ & $0.17 \pm 0.04 / \mathrm{xxx}$ & $0.09 \pm 0.04 * / \mathrm{xxx}$ \\
\hline Fourth & $0.03 \pm 0.02 * / \mathrm{xxx}$ & $0.05 \pm 0.03 / \mathrm{xxx}$ & $0.03 \pm 0.02 / \mathrm{xxx}$ & 0.00 \\
\hline
\end{tabular}

Significant differences between the estimated and expected values of Manly's index; in terms of numbers expected values are 0.45, $0.27,0.20,0.08$; significant differences are indicated by asterisks, $*: P<0.05, * *: P<0.01, * * *: P<0.001$.; in terms of biomass the expected values are: $0.21,0.27,0.30,0.21$ for each instar independent of species, significant differences are indicated by $\mathrm{x}: P<0.05$, xx: $P<0.01$, xxx: $P<0.001$. 
TABLE 4. Biomass in mg (mean \pm SE) consumed by fifth instar nymphs of Macrolophus pygmaeus when offered 10 nymphs of each instar of Myzus persicae and Macrosiphum euphorbiae, alone or together.

\begin{tabular}{lccccc}
\hline & \multicolumn{2}{c}{ One species alone } & & \multicolumn{2}{c}{ Two species together } \\
\cline { 2 - 3 } \cline { 5 - 6 } Instar & M. persicae & M. euphorbiae & & M. persicae & M. euphorbiae \\
\hline First & $0.08 \pm 0.01 \mathrm{Aa} \alpha$ & $0.17 \pm 0.01 \mathrm{Ba} \alpha$ & & $0.06 \pm 0.01 \mathrm{Aa} \alpha$ & $0.11 \pm 0.01 \mathrm{Ba} \alpha$ \\
Second & $0.15 \pm 0.02 \mathrm{Ab} \alpha$ & $0.14 \pm 0.02 \mathrm{Aab} \alpha$ & & $0.12 \pm 0.01 \mathrm{Ab} \alpha$ & $0.09 \pm 0.01 \mathrm{Ba} \alpha$ \\
Third & $0.15 \pm 0.01 \mathrm{Ab} \alpha$ & $0.12 \pm 0.02 \mathrm{Aab} \alpha$ & & $0.14 \pm 0.02 \mathrm{Ab} \alpha$ & $0.05 \pm 0.02 \mathrm{Bb} \beta$ \\
Fourth & $0.09 \pm 0.02 \mathrm{Aa} \alpha$ & $0.08 \pm 0.03 \mathrm{Ab} \alpha$ & & $0.10 \pm 0.02 \mathrm{~b} \alpha$ & 0.00 \\
\hline
\end{tabular}

Values with the same upper case letters were not significantly different between species for a given instar when offered alone or together. Values with the same lower case Roman letters were not significantly different among instars (within each column). Values for each instar with the same lower case Greek letters were not significantly different between the "one species alone" and the "two species together" treatments for each species.

based on its predation rate and the biomass consumed (Tables $2 \mathrm{a}$ and $2 \mathrm{~b}$ ). However, when unequal numbers of nymphs of $M$. persicae were used, although predation rate was higher on first instars (Table 3a), preference in terms of numbers was higher for second instar and in terms of biomass consumed for the first followed by the second instar (Table 3b). Thus, M. pygmaeus prefers to feed on first and second instar M. persicae. Consequently, the evaluation of the predation rate on M. persicae, not only when offered in equal but also in unequal numbers, showed that preference is dependent on the relative ratios of prey.

For M. euphorbiae, preference expressed in numbers or biomass consumed was always greater for first instars (Tables 2-5). The first instar is much more suitable than other instars of M. euphorbiae for M. pygmaeus.

It is assumed that prey encounter rate and energy gain scale positively with prey size and consequently, predators should ideally consume larger prey (Charnov, 1976) as is also predicted by optimal foraging theory (Stephens \& Krebs, 1986). However, increase in prey size often results in greater handling times, consumption times and an increased mortality risk (Pastorok, 1981; Sabelis, 1992). In our case, M. persicae was the preferred prey. The reason for this result is unlikely to be due to a difference in the nutritional values of the two aphid species since M. pygmaeus completes its development in a similar period on both aphids (Perdikis \& Lykouressis, 2000). It could be attributed to the higher mobility of $M$. euphorbiae which can escape predators more easily than M. persicae. In a related study, the higher preference for $M$. persicae over M. euphorbiae individuals of comparable size was attributed to the different reactions of the aphids when attacked by a predator (Meyling et al., 2003).

The preference of $M$. pygmaeus for second instar $M$. persicae and first instar M. euphorbiae, which are very similar in weight, indicates that the "size" of the prey (as indicated by their biomass) plays a crucial role in preference. Larger prey might not be preferred for the reasons explained above, whereas, if only small prey are available, increased searching time may place an upper limit on the number of prey items consumed which may result in insufficient energy being obtained by the predator (Crawley \& Krebs, 1992; Roger et al., 2000). Thus, M. pygmaeus can select suitable prey from the different prey types available.

In conclusion, the results presented here show that the effectiveness of M. pygmaeus in reducing aphid numbers is dependent not only on the prey species, but also on the relative abundance of each aphid instar in the population. Prey preference and biomass consumption indices revealed that M. pygmaeus prefers first and second instar M. persicae and first instar M. euphorbiae. These results contribute to our understanding of the effectiveness of $M$. pygmaeus in aphid biological control. They also indicate that experiments on predation rate should be accompanied by studies on prey preference and biomass consumption if one is aiming in determining prey utilization in natural environments.

ACKNOWLEDGEMENTS. The authors would like to thank A. Fantinou of the Agricultural University of Athens, for the corrections and constructive suggestions she made on the manu-

TABLE 5. Biomass in mg (mean \pm SE) consumed by fifth instar nymphs of Macrolophus pygmaeus when offered 18, 11, 8 and 3 nymphs of each instar of Myzus persicae and 19, 11, 7 and 3 nymphs of each instar of Macrosiphum euphorbiae, alone or together.

\begin{tabular}{lccccc}
\hline & \multicolumn{2}{c}{ One species alone } & & \multicolumn{2}{c}{ Two species together } \\
\cline { 2 - 3 } \cline { 5 - 6 } Instar & M. persicae & M. euphorbiae & & M. persicae & M. euphorbiae \\
\hline First & $0.12 \pm 0.01 \mathrm{Aa} \alpha$ & $0.29 \pm 0.02 \mathrm{Ba} \alpha$ & & $0.10 \pm 0.01 \mathrm{Aa} \alpha$ & $0.12 \pm 0.01 \mathrm{Aa} \beta$ \\
Second & $0.18 \pm 0.02 \mathrm{Ab} \alpha$ & $0.17 \pm 0.03 \mathrm{Ab} \alpha$ & & $0.14 \pm 0.02 \mathrm{Ab} \alpha$ & $0.07 \pm 0.02 \mathrm{Bb} \beta$ \\
Third & $0.11 \pm 0.02 \mathrm{Aa} \alpha$ & $0.08 \pm 0.02 \mathrm{Ac} \alpha$ & & $0.08 \pm 0.02 \mathrm{Aa} \alpha$ & $0.02 \pm 0.01 \mathrm{Bc} \beta$ \\
Fourth & $0.02 \pm 0.01 \mathrm{Ac} \alpha$ & $0.04 \pm 0.02 \mathrm{Ac}$ & & $0.013 \pm 0.01 \mathrm{c} \alpha$ & 0.00 \\
\hline
\end{tabular}

Values with the same upper case letters were not significantly different between species for a given instar when offered alone or together. Values with the same lower case Roman letters were not significantly different among instars (within each column). Values for each instar with the same lower case Greek letters were not significantly different between the "one species alone" and the "two species together" treatments for each species. 
script. Many thanks are also due to J. Bale of the University of Birmingham who kindly contributed to the linguistic improvement of the manuscript.

\section{REFERENCES}

Albajes R. \& Alomar O. 1999: Current and potential use of polyphagous predators. In Albajes R., Lodovica Gullino M., van Lenteren J.C. \& Elad Y. (eds): Integrated Pest Disease Management in Greenhouse Crops. Kluwer Academic Publishers, Dordrecht, pp. 265-275.

Charnov E.L. 1976: Optimal foraging, the marginal value theorem. Theor. Popul. Biol. 9: 129-136.

CHEsson J. 1983: The estimation and analysis of preference and its relationship to foraging models. Ecology 64: 1297-1304.

Crawley M.J. \& Krebs J.R. 1992: Foraging theory. In Crawley M.J. (ed.): Natural Enemies. Blackwell Scientific Publications, Oxford, pp. 90-114.

Enkegaard A., BrødsgaArd H.F. \& Hansen D.L. 2001: Macrolophus caliginosus: Functional response to whiteflies and preference and switching capacity between whiteflies and spider mites. Entomol. Exp. Appl. 101: 81-88.

Evans E.W., Richards D.R. \& Kalaskar A. 2004: Using food for different purposes: female responses to prey in the predator Coccinella septempunctata L. (Coleoptera: Coccinellidae). Ecol. Entomol. 29: 27-34.

Hagler J.R. \& Cohen A.C. 1991: Prey selection by in vitroreared and field-reared Geocoris punctipes. Entomol. Exp. Appl. 59: 201-205.

Krebs J.R. \& McCleery R.H. 1984: Optimizations in behavioural ecology. In Krebs J.R. \& Davies N.B. (eds): Behavioural Ecology, an Evolutionary Approach. Blackwell Scientific, Oxford, pp. 91-121.

Lykouressis D.P., Perdikis D.Ch. \& Chalkia Ch.A. 2000a: The effects of natural enemies on aphid populations on processing tomato. Entomol. Hellenica 13[1999-2000]: 35-42.
Lykouressis D., Perdikis D. \& Tsagarakis A. 2000b: Polyphagous mirids in Greece: Host plants and abundance in traps placed in some crops. Boll. Lab. Entomol. Agr. Fillippo Silvestri 56: 57-68.

Lykouressis D.P., Perdikis D.Ch. \& Michalaki M.P. 2001: Nymphal development and survival of Macrolophus pygmaeus Rambur (Hemiptera: Miridae) on two eggplant varieties as effected by temperature and presence/absence of prey. Biol. Control 20: 222-227.

Manly B.F.J., Miller P. \& CoOK L.M. 1972: Analysis of a selective predation experiment. Am. Nat. 106: 719-736.

Meyling N., EnKegaard A. \& Brodsgaard H. 2003: Two Anthocoris bugs as predators of glasshouse aphids - voracity and prey preference. Entomol. Exp. Appl. 108: 59-70.

PASTOROK R.A. 1981: Prey vulnerability and size selection by Chaoborus larvae. Ecology 62: 1311-1324.

Perdikis D.Ch. \& LyKouRessis D.P. 2000: Effects of various items, host plant and temperature on the development and survival of Macrolophus pygmaeus Rambur (Hemiptera: Miridae). Biol. Control 17: 55-60.

Perdikis D.Ch., Lykouressis D.P. \& Economou L.P. 1999: The influence of temperature, photoperiod and plant type on the predation rate of Macrolophus pygmaeus on Myzus persicae. BioControl 44: 281-289.

Roger C., Coderre D. \& Boivin G. 2000: Differential prey utilization by the generalist predator Coleomegilla maculata lengi according to prey size and species. Entomol. Exp. Appl. 94: $3-13$.

Sabelis M.W. 1992: Predatory arthropods. In Crawley M.J. (ed.): Natural Enemies. Blackwell Scientific Publications, Oxford, pp. 225-264.

SAS Institute. 2001: JMP A Guide to Statistics and Data Analysis.Version 4.0.2. SAS Institute Inc., Cary, NC.

Stephens D.W. \& Krebs J.R. 1986: Foraging Theory. Princeton University Press, Princeton, 247 pp.

Received March 29, 2006; revised and accepted December 4, 2006 